\title{
The D-Learning Alternative during COVID-19 Crisis: A Preliminary Evaluation based on Kirkpatrick's Model
}

\author{
By Jalal Ismaili ${ }^{*}$ \& El Houcine Ouazzani Ibrahimi ${ }^{ \pm}$
}

\begin{abstract}
The COVID-19 pandemic has placed schools around the world under unprecedented challenges where saving students' lives is placed ahead of education as a priority. Within these conditions of distress and uncertainty, education authorities had no choice but to move traditional classes into online ones to ensure the sustainability of studies. The abrupt inevitable decision has been a first for most if not all teachers and students who are invited to cope with a totally new teaching/learning model without necessarily having prior experience in Distance Learning in terms of apparatus or techniques. This study comes as an in-progress appraisal of the D-learning scenarios proposed by Moulay Ismail University (MIU) in Meknes, Morocco, based on a two-level evaluation model (Reaction and Learning) proposed by Daniel Kirkpatrick. It is a real-time evaluation of a learning strategy that has long been considered optional for some students, to become, rather, a plan A constituent for many education departments around the world. The study investigates areas of success and failure from the students' perspective via 4 sub-indicators: accessibility, autonomy, retention and psychological impact. The study concludes that the figures can be more reassuring about the D-learning experience in MIU once issues related to connectivity and communication are redressed.
\end{abstract}

Keywords: d-learning, e-learning, pandemic, COVID-19, Kirkpatrick's model, information and communication technology

\section{Background}

Following the Moroccan government's decision of complete lockdown to prevent any uncontrolled spread of COVID-19, the ministry of education took measures to ensure the continuity of studies by, for instance, placing at the disposal of universities access to TV and radio channels to broadcast lectures and courses on multiple topics for different areas of knowledge. By the same token, universities tried to be more autonomous by setting up their own D-learning platforms and social media channels, recording their authentic video podcasts and sharing access to prestigious library databases. As the confinement is going to last longer than expected in many parts of the globe, governments are calling their citizens to cope with the virus and the new mode of living. So far, uncertainty prevails for teachers, students and decision-makers on whether the students will be able to resume their studies at schools as normal as they did before the pandemic.

\footnotetext{
*Assistant Professor, The Higher Institute of Technology, Moulay Ismail University, Morocco. ${ }^{ \pm}$Professor, Laboratory of Discourse, Creativity, Society and Religions, Faculty of Letters and Humanities Sais, Sidi Mohamed Ben Abdellah University, Morocco.
} 
D-learning will probably continue to serve as a plan B for many schools around the globe, especially those challenged by large size classes where social distancing is highly required. So far, the official bulletins and communications issued by the government (Minister of National Education 2021, MapNews 2021) tend to promote an assuring discourse that has not been empirically verified. Because it is of paramount importance to retrieve feedback from students to evaluate the effectiveness of the experience and pinpoint areas of imperfection that hinder the attainment of optimal results, this study comes to provide a preliminary concise evaluation of the D-learning model adopted by The MIU affiliate Higher Institute of Technology. The school that hosts students from divergent communities and social milieus (urban communities, suburban towns and remote villages ...) should serve as a typical case study that fully satisfies the criteria of representation and randomness. The institute takes advantage of the university's digital resources and apparatus whose added value is yet to be proven during these peculiar conditions. The evaluation examines the process's Accessibility (students' ability to access the resources placed at their disposal to maintain the continuity of studies), Autonomy (the students' ability to process/digest the course material provided by the faculty), Retention (the student's ability to provide pertinent feedback and perform well during exams) and Psychological impact (the student's ability to cope with the conditions that characterise the D-learning model)

The paper is divided into 6 sections and organised as follows: The first section discusses the significance of Information and Communication Technology (ICT) before the pandemic, followed by a review of ICT programs in Morocco. The related work section is dedicated to the state of the art relative to D-learning before and during the pandemic in Morocco. The practical part starts with a briefing about the methodology, and results. Finally, comes the implications and interpretations section and conclusion.

\section{E-Learning and D-Learning in Morocco: GENIE Programme}

The ministry of national education in Morocco celebrates the programme of Generalisation of Information and Communication Technologies in Education (GENIE) as the most elaborate collaborative ICT programme in the country. In order to approximate the global ever-evolving research in Information and Communication Technology for Education (ICTE), the Moroccan ministry of education launched the Generalisation of ICT in Education Programme (GENIE) in 2006 to establish a nationwide strategy that systematises the abrupt occasional initiatives by teachers and voluntary associations whose effectiveness remained, for a while, questionable and more intuitive.

In its initial version, GENIE was granted a period of three years with three principal axes; infrastructure, training and digital resources:

Infrastructure: setting up multimedia environments with internet connection for students in partnership with international hardware and software companies. Each Regional Academy of Education and Training (RAET) 
places at the disposal of affiliated teachers 2 multimedia rooms for professional training.

Training: It was based on a waterfall approach. At the central unit in Rabat, a group of "Master Trainers" is selected and trained by experts. These Master Trainers will undertake the mission of coaching 4 regional coaches from each of the 16 RAETs. These 4 coaches would, in return, give training to 2 or 3 school staff who should eventually transfer the training to their co-workers.

Digital resources: also called content development aims at providing digital resources and establishing a national laboratory of digital resources and a national ICTE web portal.

GENIE II (2009-2013) was particularly characterised by the introduction of a fourth axis to be added to infrastructure, training and digital resources; that is of usage development. The new mission sets a number of priority objectives such as the acquisition of digital resources, launching an ICTE web portal, organising sensitisation campaigns and sharing workshops. It also investigates and tracks what the end users do with ICT (Ennda 2010). Although the pace of realisation has tangibly improved, the programme fell short again of achieving $100 \%$ of the target goals.

Within the Strategic Vision of Reform 2015/2030 launched by the Supreme Council for Education, Training and Scientific Research (SCETSR), particularly in the sixth lever, the council calls for the equipment of educational institutions with the necessary infrastructure, equipment, didactic material... and digital libraries... It also calls for the equipment of classrooms with audio-visual aids and ICTs. The vision has lifted the ban on GENIE and freed it from any fixed-term plans. Starting from 2016, the programme has for the first time opened up on Open-Source programmes thanks to the National Laboratory of Digital Resources (NLDR) and the Morocco-Korean Centre of ICTE Training (MKCT) by means of several projects.

\section{Programme Evaluation: Donald Kirkpatrick's Four Levels of Evaluation}

In 1959, Donald Kirkpatrick proposed 4 basic levels of evaluation published in the Training and Development Journal to make up a reference mark for most, if not all, subsequent models of evaluation (Kirkpatrick 2009). When launched for the first time, it made part of a project on evaluating a supervisory training programme, yet the model's simplicity, effectiveness and comprehensiveness required in any evaluation process makes it a good fit for a wide range of study fields including medicine, higher education, vocational education in enterprises, blended learning, ICT, etc. (Moldovan 2016, Tamkin et al. 2002). Because of the ever-evolving research on evaluation, Kirkpatrick had to consistently adapt or update the levels' guidelines, while the four levels (reaction/learning/ behaviour/ evaluation) remained unchangeable. The levels are also referred to as steps or even taxonomy as each one leads to a more elaborate level that is "more difficult and 
time-consuming, but ... also provides more valuable information" (Kirkpatrick and Kirkpatrick 2006).

1. Reaction: Kirkpatrick also calls it a "measure of customer satisfaction" (Kirkpatrick 1996). A customer according to him is anyone who takes part of the training course whether they paid for it or not, whether it was voluntary or forced by an organisation. Although the model was conceived about 60 years ago, Kirkpatrick adopts a bottom-up approach to the evaluation process as he believes that the positive reactions of trainees are important for trainers and for those who make public programs.

2. Learning: This step measures the effectiveness of learning process and the impact it made on the learners at one of these levels: knowledge, skills or attitudes. Certain programs target enhancing one of these competencies such as languages or engineering, while others can incorporate integrative approaches to enhance two or even three such as motivation and communication courses. The evaluator, there- fore, must determine clearly their objectives to remain on a safe side.

3. Behaviour: This step is referred to as transfer of training. It examines whether the training has impacted the learner's behaviour at work or school as intended by the institution after attending a particular training. Kirkpatrick, as stated earlier in this chapter, draws attention to the fact that institutions that carry out evaluation are likely to skip behaviour and results evaluation; nevertheless, some institutes bypass the first two levels to address particularly behaviour evaluation from the very beginning. $\mathrm{He}$ disapprovingly does not recommend the procedure and even calls it a "serious mistake" because a programme's failure to deliver at the level of behaviour does not impulsively mean that it failed to deliver at the level of reaction and learning.

4. Results: This step examines the final results and the effects of the training on learners and institution as well. Optimal results should, for instance, reveal an increase of profit, better quality products, better graduation rates, cost reduction, reinforcement of desirable practices and values, lower drop-out rates, etc. "It is important to recognise that results like these are the reason for having some training programmes. Therefore, the final objectives of the training programme need to be stated in these terms" (Kirkpatrick 2009).

\section{Related Work}

Academic research on D-learning during the COVID-19 pandemic is still in progress in many parts of the world. It will certainly take time to conduct a thorough appraisal of this unprecedented experience. Meanwhile, a number of research papers have tried to share perspectives from different parts of the world

In a study entitled "Influence of COVID-19 confinement on students' performance in higher education" Gonzalez et al. (2020) analyse the effects of 
COVID-19 confinement on the autonomous learning performance of students in higher education at Universidad Autónoma de Madrid (Spain). They compare the differences in assessments before and during the pandemic by dividing students into two groups; a control group from previous years and an experimental group that was interrupted because of the confinement. According to the study, there is a significant positive effect of the COVID-19 confinement on the students' performance.

In a paper entitled "Global impact of COVID-19 on education systems: the emergency remote teaching at Sultan Qaboos University", Osman (2020) highlights the impact of COVID-19 pandemic on the education system in the Sultanate of Oman. The paper provides an analytical description of the Emergency Remote Teaching Plan in higher education and how the experience has changed the teaching and learning landscape.

In a paper entitled "Innovations in teacher education at the time of COVID19: an Australian perspective" Scull et al. (2020) address the Australian response to the emerging COVID-19 challenges to the education sector and details how the Australian university implemented a number of innovative solutions to move online. The conversion incorporates synchronous and asynchronous learning opportunities. The paper tries to investigate the factors that contributed to fostering high levels of interaction of pre-service teachers, particularly by means of interviews with professors. Scull et al. provide a number of cues and key lessons that "might benefit others looking for ways to provide high-quality teacher education programmes during and after the COVID-19 pandemic."

As for the Moroccan context, Oubibi and Wei (2017) argue that e-learning and Massive Open Online Courses (MOOCs), as popular forms of D-learning, are becoming an option no more; they rather represent an imminent conversion towards the undisputed digitalised future of the university. According to them, universities are facing substantial financial and technical imperatives that make elearning, via blended learning model and (MOOCs), a tempting solution for the university and for the students in China and Morocco. The study also highlights the disparity of readiness for change between Morocco and China in favour of the latter due to investments in ICT placed at the disposal of Chinese universities, teachers and students. In an effort to contribute to promoting D-Learning in Moroccan universities, Riyami et al. (2016) propose a pedagogical plan using MOOC for teacher training. It is a chart of international MOOCs available for university professors which identifies trainings customised to the beneficiaries' areas of expertise and levels. The study also proposes a management plan to motivate teachers during the training.

Bouziane (2019) conducted an exhaustive synthetic survey of master and doctoral theses in which he investigated success and failure experiences relative to ICT in education in Morocco. The study affirms that online learning, in particular, is not given the attention it is worth by decision makers, which proved to be indeed a strategic pitfall during the Corona pandemic. Bouziane checked the level of Morocco's e-readiness to integrate into the information society based on a Harvard e-readiness assessment framework (Bouziane, 2019). He concluded that, apart from networked economy, the other indicators of network access, networked 
society and network policy scored a satisfactory level of preparedness. Whereas indicators and sub-indicators of relevance to the Moroccan university scored lower than average. In another study conducted by Elaasri and Bouziane (2019), they evaluate seven online courses in a digital working space of Hassan II university using Quality Matters rubrics. They concluded that the courses fell short of delivering satisfactory results as far as the quality standards are concerned

The World Economic Forum (2020) showcased the surge of demand for Dlearning technologies, particularly online learning platforms after the schools' shutdown marking the largest "online movement" in the history of education. According to the WEF, the challenges of limited staff training, insufficient bandwidth and little preparation may lead to poor user experience that is "unconducive to sustained growth". Yet there is a good chance that a new hybrid model of education will develop with significant benefits (World Economic Forum 2020). The challenges of accessibility to hardware and internet that exist between privileged and underprivileged communities (sometimes within the same nation) are hard to deny or overlook; still, studies have shown that the students' retention capacity jumps higher (25-60\%) while taking online courses compared to classroom courses, according to the WEF. The datum might be justified by the fact that D-learning provides larger margins of autonomy and better customised learning pace (Andresen et al. 2002). These pedagogical and economic benefits, according to the WEF, imply that this new education model will be adopted for good and are not temporary.

To sum up, the review of D-learning literature suggests that the 2019 pandemic is but a trigger that released the process of inevitable radical change. It was just a matter of time before we witness a revolutionary change towards a more digitised model of education. Some countries have foreseen the inevitable need to invest in infrastructure, hence they acted and planned on a long run basis; others did not act until change has become urgent and forcible.

\section{Methodology}

The appraisal of distant learning in Morocco, at this point, imposed by the COVID-19 pandemic is important but may not yield a comprehensive ultimate verdict about the whole teaching model. The relevance resides in the fact that it pinpoints areas of weakness to rectify and areas of strength to capitalise on. The authors, thus, prefer to restrict the evaluation to Kirkpatrick's (2009) first two levels; reaction and learning. The reaction level takes into account the abundance of sufficient material, adequate learning environment, the students' interaction with peers and instructors and the students' impression about the experience. Positive feedback at this level does not necessarily mean that the learning process has been effective and successful. The next level (learning) gauges the students' performance and intake. The attainment of the objectives set forth by the teacher is detrimental to the potential sustainability of D-learning model post the pandemic. 


\section{Population of the Study}

The population of the study consists of 136 first-year students from the Higher Institute of Technology. The students, whose majors are Business and Computer Science, descend from different parts of the country and divergent social milieus. They were surveyed by means of Google Forms during the first two weeks of May 2020 (7 weeks post the beginning of school shutdown). The survey observed the requirements of anonymity, randomness, representation and disclosure of the survey purpose. The authors notice that the answers were flowing at a high speed compared to other surveys conducted earlier for other purposes (Ismaili and Ouazzani Ibrahimi 2017). Over 85\% of valid responses were generated in less than 4 hours, which may be explained by the students' alertness to updates and possession of gadgets to communicate with their school.

\section{Rubrics of Survey}

The survey incorporates 4 rubrics. Accessibility, Autonomy and Psychological impact would answer inquiries related to Kirkpatrick's level of Reaction, while the Retention rubric would provide answers relative to the next level that is Learning. Each rubric incorporates 5 items to answer.

- Accessibility: The rubric surveys the students' possession of ICT devices, access to the university's D-learning platform and frequency of use.

- Autonomy: The rubric surveys the students' ability to sustain selfregulated activities without direct interference from teachers.

- Psychological impact: the rubric examines the acceptance of the Dlearning model as a constant component of future syllabi, in addition to its role in relieving levels of stress and tension.

- Retention: The rubric surveys the students' capability to retain information they receive online and their confidence in reproducing the inputs.

\section{Data Analysis}

The process of data analysis is based on quantitative and qualitative methodology and is carried out using IBM's Statistical Package for the Social Sciences V21. The analysis investigates areas of correlation between 20 variables; 19 of which are ordinal while 1 is nominal to help better explain the achieved results. Correlation of these variables would eventually lead to building connection(s) between the 4 rubrics of research and understand their mechanisms of interaction. The process will also help draft implications and recommendations for interested stakeholders. The 19 questionnaire items are to be answered on a scale from 1 to $5 ; 1$ stands for highly disagree, while 5 translates into highly agree. The results are considered positive/satisfactory when the scale average is at least $4 / 5$, and it is negative/unsatisfactory when it goes below $2 / 5$. The analysis of each rubric is summed up with an index reference set at 3 based on the Mean. Failure to 
achieve that number implies that immediate action by stakeholders is required to mend the gap.

\section{Results}

Accessibility

This rubric examines the abundance of the fundamental requirements to make the D-learning possible to take place. The items below (see Figure 1) depict the availability of gadgets, internet, engagement, and easiness of platform use.

\section{Figure 1. Accessibility}

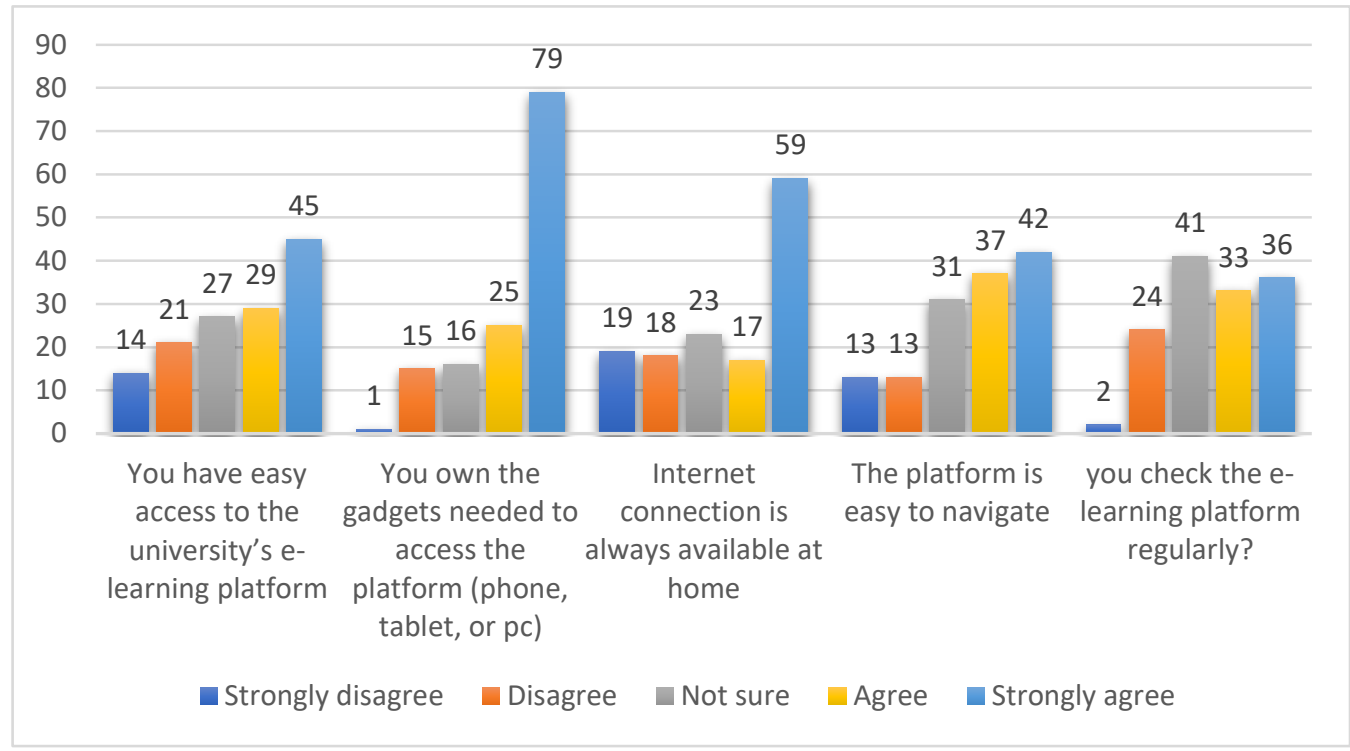

According to the survey (Figure 1), $54.5 \%$ of the sample students find accessibility to the university's D-learning platform (FAD) very easy while $25.7 \%$ find it a bit challenging. The observed affinity with figures related accessibility to internet access may correlate as $55.9 \%$ of students do have access to internet while $27.2 \%$ do not. Despite the fact that Moroccan internet operators have engaged in providing free access to the ministry of education's platforms "except YouTube"1, the procedure remains of limited impact for higher institutes given that a big number of lectures are uploaded in video format on YouTube. By the same token, $51 \%$ of students may be described as regular visitors to the platform, $30 \%$ frequent visitors, while $19 \%$ are irregular users. The most satisfying results in this rubric are those related to ownership of smart gadgets given that $76.5 \%$ of students constantly possess a laptop, a smartphone or a tablet, while only $11.7 \%$ do not. The $11.8 \%$ who answered "not sure" may have to use a shared device at home.

${ }^{1}$ https://www.moroccoworldnews.com/2020/03/297143/moroccos-telecommunication-operato rs-offer-free-internet-access-to-education-websites/. 
Table 1. Accessibility Index Reference based on Mean

\begin{tabular}{|l|c|c|c|c|c|}
\hline & $\begin{array}{c}\text { Easy access } \\
\text { to the } \\
\text { platform }\end{array}$ & $\begin{array}{c}\text { Ownership } \\
\text { of gadgets }\end{array}$ & $\begin{array}{c}\text { Internet } \\
\text { availability }\end{array}$ & $\begin{array}{c}\text { Easy to } \\
\text { navigate } \\
\text { platform }\end{array}$ & $\begin{array}{c}\text { Regularity } \\
\text { of visits }\end{array}$ \\
\hline Mean & 3.5147 & 4.2206 & 3.5809 & 3.6029 & 3.5662 \\
\hline $\mathrm{N}$ & 136 & 136 & 136 & 136 & 136 \\
\hline $\begin{array}{l}\text { Std. } \\
\text { Deviation }\end{array}$ & 1.36075 & 1.07972 & 1.49347 & 1.27819 & 1.10690 \\
\hline
\end{tabular}

As the five items have scored higher than the index reference 3 , and given that the average mean is 3.69 , it is concluded that the accessibility results are satisfactory and indicate the abundance of decent conditions for D-learning to operate (Table 1).

\section{Autonomy}

Autonomy rubric examines the participants' ability to sustain self-regulated activities, and how well they can do relying on their prerequisite skills and competencies. In the absence of peers and teachers "physically" around, it is important to know how the students handle learning challenges of obscurity, lack of understanding and lagging behind their peers.

\section{Figure 2. Autonomy}

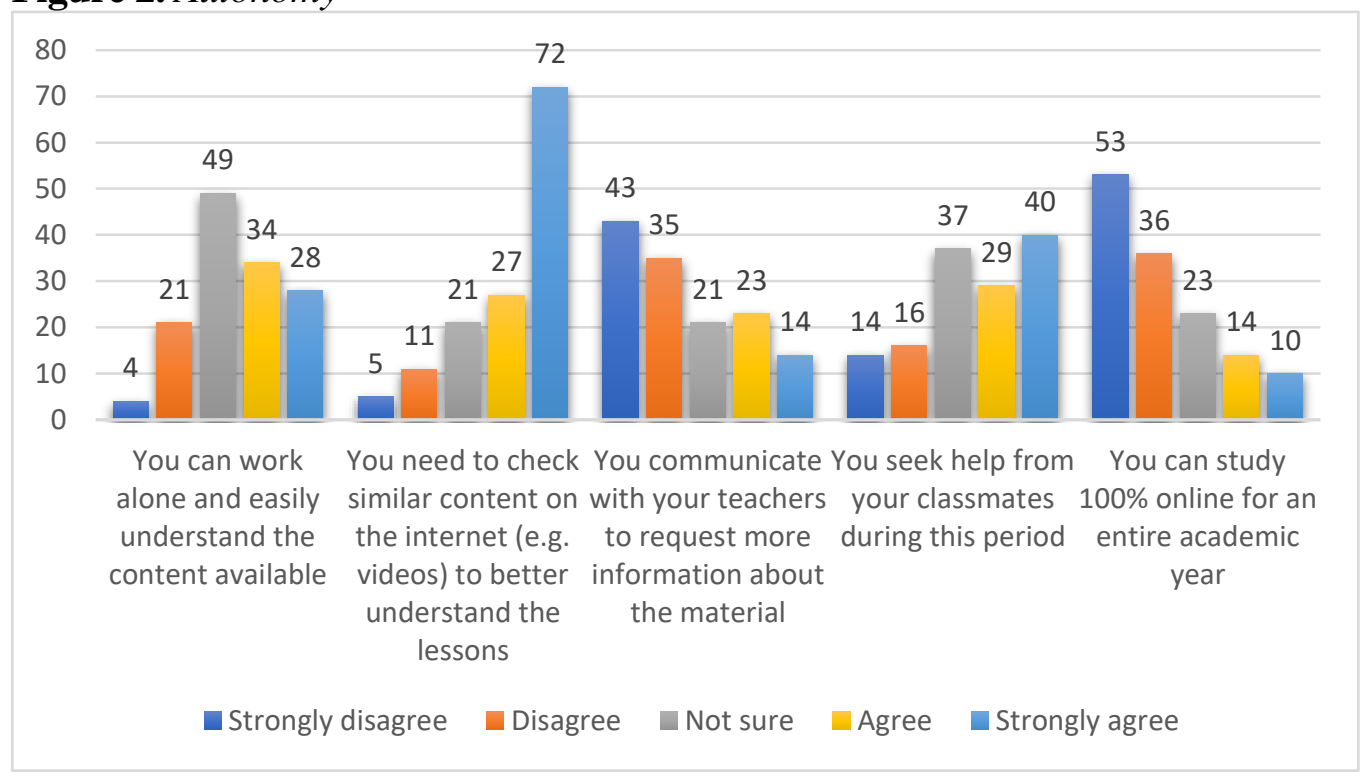

Figure 2 indicates that $45.6 \%$ of students can deal with the resources available online in full autonomy, while $18.3 \%$ encounter some challenges. $36.1 \%$ say they are not sure, and it is completely understandable since average students in the classroom need a bit of help before they can grasp the lessons and digest the difficulties. The study finds that the students deploy their intuitive autolearning mechanisms as $72.8 \%$ diversify their resources by consulting similar content on 
the internet. Networking with peers is another mechanism used as $50.7 \%$ of students feel the need to stay connected with their classmates to seek help, coordinate and share material. $22.1 \%$, however, do not feel like they need to. One striking finding about autonomy rubric is the modest level of direct communication with professors. It is true that the university, mainly the faculty, invested a huge effort setting up a D-learning strategy and compiling material in a short time ${ }^{2}$, yet direct communication between students and teachers would result in a more significant outcome. The last question examines the participants' readiness to go $100 \%$ online for the upcoming year, and the idea is not welcomed by $65.5 \%$ of participants. The reactions suggest that the participants are not ready to trade the traditional classroom for a virtual one, at least for the time being. Only $17.7 \%$ do not mind the transition.

Table 2. Autonomy Index Reference based on Mean

\begin{tabular}{|c|c|c|c|c|c|}
\hline & $\begin{array}{c}\text { Full } \\
\text { autonomy }\end{array}$ & $\begin{array}{c}\text { Checking } \\
\text { other } \\
\text { sources }\end{array}$ & $\begin{array}{c}\text { Communicating } \\
\text { with professors }\end{array}$ & $\begin{array}{c}\text { Communicating } \\
\text { with classmates }\end{array}$ & $\begin{array}{c}\text { Going } \\
\mathbf{1 0 0 \%} \\
\text { online next } \\
\text { year }\end{array}$ \\
\hline Mean & 3.4485 & 4.1029 & 2.4853 & 3.4779 & 2.2059 \\
\hline N & 136 & 136 & 136 & 136 & 136 \\
\hline $\begin{array}{c}\text { Std. } \\
\text { Deviation }\end{array}$ & 1.07373 & 1.15649 & 1.36075 & 1.30507 & 1.26560 \\
\hline
\end{tabular}

The index reference has been attained in 3 items and has not in 2 others (Table 2). Still, the average mean of the 5 variables is 3.13 , which is satisfactory. The available content as well as the deployment of their autolearning strategies have scored satisfactory results, while direct communication with faculty is yet to be addressed by the university. Communication does not only help in the process of learning, but it is also a source of moral reassurance for students. Certainly, shifting to $100 \%$ online courses is an ominous proposition the authors do not endorse as it suggests the confinement will stay for a long time. Thus, the low mean recorded is not considered as negative or fit to be regarded as an index reference.

\section{Psychological Impact}

The psychological impact examines the students' emotional reaction to this experience in addition to identifying the affective filter if there is any. It also verifies whether any prior exposure to D-learning before the pandemic has made the full online transfer any easier.

\footnotetext{
${ }^{2}$ http://www.mapexpress.ma/actualite/societe-et-regions/covid-19-cinq-questions-au-presidentluniversite-moulay-ismail-meknes/
} 
Figure 3. Psychological Impact

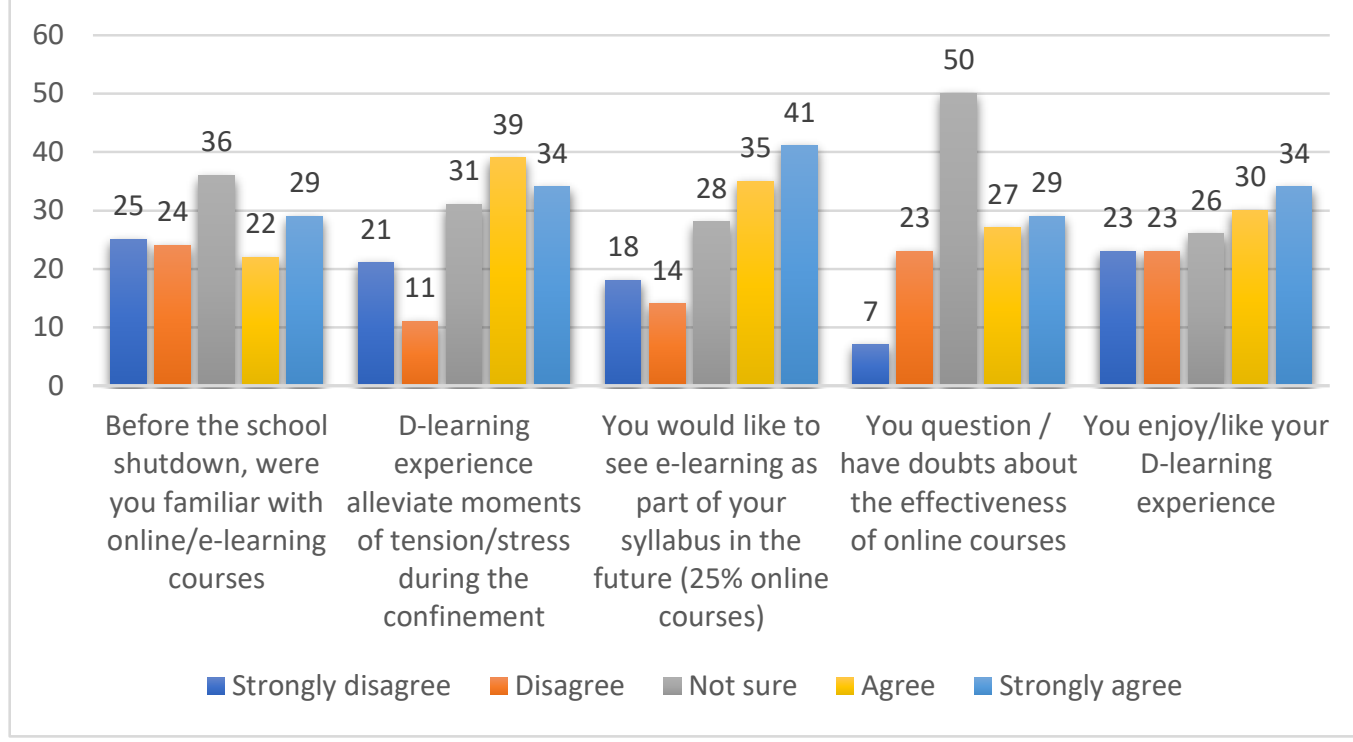

As Figure 3 illustrates, the first question of this rubric tries to detect whether students have been prepared to work online before the lockdown. Any preceding initiation would alleviate feelings of floundering and getting lost for novice students with nil D-learning experience. $37.5 \%$ of participants acknowledge having a previous e-learning experience, while $36 \%$ stated that they do not. The $20.5 \%$ left of the sample (undecided) suggests that some students have doubts about their technology skills and are not confident to call themselves experienced D-learners. $41.2 \%$ of surveyed students doubt the equivalence of D-learning to actual classroom learning, while $22 \%$ have high confidence in technology effectiveness. The good news for D-learning advocates is finding that it helps alleviate feelings of stress and tension during the confinement for $53.7 \%$ of surveyed students. $23.5 \%$ say it does not because they have accessibility issues on the first place, especially with internet as they explain. In addition, $47.1 \%$ think the D-learning experience is enjoyable at the personal level, opposite to $33.8 \%$ who do not. When asked if they want D-learning to be partially incorporated $(25 \%)$ in next year's syllabus, almost 56\% welcomed the idea. Only $23.5 \%$ categorically rejected the proposition as they will have to deal with the current challenges again; mainly those mentioned in the accessibility rubric.

Table 3. Psychological Impact Index Reference based on Mean

\begin{tabular}{|l|c|c|c|c|}
\hline & $\begin{array}{c}\text { Familiarity } \\
\text { with D- } \\
\text { learning }\end{array}$ & $\begin{array}{c}\text { D-learning } \\
\text { alleviates } \\
\text { Stress }\end{array}$ & $\begin{array}{c}\text { Incorporating } \\
\mathbf{2 5 \%} \text { D- } \\
\text { learning } \\
\text { Permanently }\end{array}$ & $\begin{array}{c}\text { Enjoyment of } \\
\text { the experience }\end{array}$ \\
\hline Mean & 3.0441 & 3.3971 & 3.4926 & 3.2132 \\
\hline $\mathrm{N}$ & 136 & 136 & 136 & 136 \\
\hline Std. Deviation & 1.39240 & 1.35690 & 1.36624 & 1.42677 \\
\hline
\end{tabular}


Since the item relative to doubts about D-learning is not applicable to index referencing and may not serve as an objective to target, it was omitted from Table 3. The four other items scored satisfactory results ranging between 3.04 and 3.49. The average mean of psychological impact (3.28) is likely to improve once the issues stated above are redressed.

\section{Retention}

In this rubric we study the effectiveness and return on investment of the Dlearning model. The D-learning experience may be considered a success only when the students manage to acquire or at least internalise knowledge and skills they at home.

\section{Figure 4. Retention}

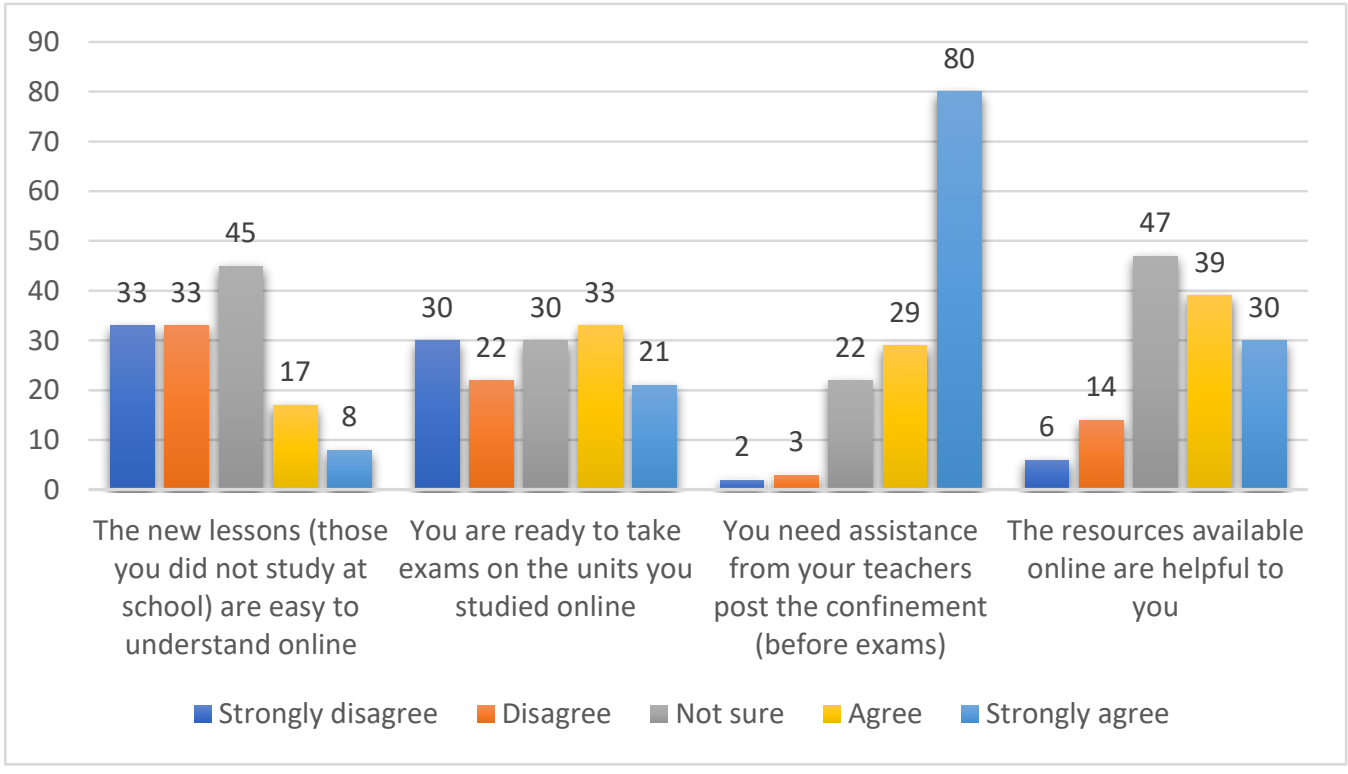

Figure 4 shows that the students encounter challenges with new lessons they are introduced to for the first time that only $18.4 \%$ find them within everyone's reach; $48.6 \%$ think they are hard to understand. It is worth mentioning that the students were only two or three weeks away from the end of modules and the remaining lessons make up only a small fraction of the syllabus. These results are consistent with those recorded by the ENSAM (see the related work section). When asked about the helpfulness of content available online, $85.3 \%$ left finds it either relatively or completely helpful, whereas only $14.7 \%$ think it is not. As for their readiness to take an exam without any review or make-up classes, around $40 \%$ said they are ready and $38.3 \%$ are not, while $34.6 \%$ remained undecided. Nonetheless, the vast majority do not mind the initiative of make-up classes and review before the exams with over $80 \%$. A tiny proportion of $3.7 \%$ think they do not need it. 
Table 4. Retention Index Reference based on Mean

\begin{tabular}{|c|c|c|c|c|}
\hline & $\begin{array}{c}\text { Content is } \\
\text { easy }\end{array}$ & $\begin{array}{c}\text { Ready for } \\
\text { exam }\end{array}$ & $\begin{array}{c}\text { Assistance } \\
\text { before exam is } \\
\text { needed }\end{array}$ & $\begin{array}{c}\text { Resources are } \\
\text { helpful }\end{array}$ \\
\hline Mean & 2.5147 & 2.9485 & 4.3382 & 3.5368 \\
\hline $\mathrm{N}$ & 136 & 136 & 136 & 136 \\
\hline Std. Deviation & 1.16100 & 1.38414 & .92872 & 1.08121 \\
\hline
\end{tabular}

Table 4 above shows that the index reference of success has been achieved in two rubrics. The average mean for the retention rubric is 3.32, which is satisfactory. Students, accordingly, demonstrate their appreciation of the human factor as indispensable to any successful D-learning scenario. The resources placed at the disposal of students by their professors are doubtlessly valued. On the other hand, the weak direct communication with professors apparently affects the students' retention capabilities and confidence in their competencies. Internalising the learners' newly acquired knowledge and skills, praising hard work and correcting mistakes reinforce the process of learning and self-efficacy.

\section{Interpretations}

Many of the above findings lead us to inspect the potential correlations between variables and subsequently rubrics. Understanding the relations between variables can help interested bodies to find adequate solutions that can elevate the index references. There is still room for the university to adapt and polish the Dlearning strategy, but some solutions must be taken at a national level as they involve other parties. It is observed, for instance, that students who do not enjoy the D-learning experience are those who struggle with gadget and internet issues (see Table 5). So, if the ministry in collaboration with other ministries, donors, partners and stakeholders can fix this issue, many other issues would, hopefully, get fixed. Following are observed correlations with the authors' interpretation and personal recommendations

Table 5. Positive Correlations

\begin{tabular}{|c|c|c|c|c|c|c|}
\hline \multicolumn{7}{|c|}{ Correlations } \\
\hline & & $\begin{array}{l}\text { Envoyment of } \\
\text { the } \\
\text { experience }\end{array}$ & Full autonomy & $\begin{array}{c}\text { Contemt is } \\
\text { gasy }\end{array}$ & $\begin{array}{l}\text { Ownership of } \\
\text { gadgets }\end{array}$ & $\begin{array}{l}\text { Ready for } \\
\text { exam }\end{array}$ \\
\hline \multirow{3}{*}{$\begin{array}{l}\text { Enjoyment of the } \\
\text { experience }\end{array}$} & Pearson Correlation & 1 & $406^{\prime \prime}$ & $497^{\circ}$ & $325^{\prime \prime}$ & $.358^{\prime \prime}$ \\
\hline & Sig. (2-tailed) & & .000 & .000 & .000 & .000 \\
\hline & $N$ & 136 & 136 & 136 & 136 & 136 \\
\hline \multirow[t]{3}{*}{ Full autonomy } & Pearson Correlation & $.406^{17}$ & 1 & $.384^{2}$ & $.291^{\prime \prime}$ & $.255^{27}$ \\
\hline & Sig. (2-tailed) & .000 & & .000 & 001 & .003 \\
\hline & $\mathrm{N}$ & 136 & 136 & 136 & 136 & 136 \\
\hline \multirow[t]{3}{*}{ Content is easy } & Pearson Correlation & $497^{\prime \prime}$ & $384^{\prime \prime}$ & 1 & $316^{\prime \prime}$ & $.399^{11}$ \\
\hline & Sig. (2-tailed) & .000 & .000 & & .000 & .000 \\
\hline & $\mathrm{N}$ & 136 & 135 & 136 & 136 & 136 \\
\hline \multirow[t]{3}{*}{ Ownership of gadgets } & Pearson Correlation & $.325^{\prime \prime}$ & $291^{\prime \prime}$ & $.316^{\circ}$ & 1 & .112 \\
\hline & Sig. (2-tailed) & .000 & .001 & .000 & & .195 \\
\hline & $\mathrm{N}$ & 136 & 136 & 136 & 136 & 136 \\
\hline \multirow[t]{3}{*}{ Ready for exam } & Pearson Correlation & $.358^{\prime \prime}$ & $.255^{\prime \prime}$ & $.399^{\prime \prime}$ & .112 & 1 \\
\hline & Sig. (2-tailed) & .000 & .003 & .000 & .195 & \\
\hline & $\mathrm{N}$ & 136 & 136 & 136 & 136 & 136 \\
\hline
\end{tabular}

$*$ Correlation is significant at the 0.01 level (2-tailed). 
Table 6. Negative Correlations

\begin{tabular}{ll|r|r|}
\hline & $\begin{array}{c}\text { Correlations } \\
\text { ng with } \\
\text { professors }\end{array}$ & $\begin{array}{c}\text { D-learning } \\
\text { alleviates } \\
\text { Stress }\end{array}$ \\
\hline imunicating with & Pearson Correlation & 1 & $-.209^{*}$ \\
issors & Sig. (2-tailed) & 136 & .014 \\
& $\mathrm{~N}$ & $-.209^{*}$ & 136 \\
\hline arning alleviates & Pearson Correlation & .014 & 1 \\
is & Sig. (2-tailed) & 136 & 136 \\
\hline
\end{tabular}

Correlation is significant at the 0.05 level (2-tailed).

1. There is a significant positive correlation between ownership of gadgets and enjoyment of the D-learning experience, $r(134)=0.32, p=0.000$.

2. There is a significant positive correlation between easiness of the content and enjoyment of the experience, $r(134)=0.49, p=0.000$.

3. There is a significant positive correlation between ownership of gadgets and easiness of the content, $r(134)=0.31, p=0.000$.

4. There is a significant positive correlation between the student's feeling of autonomy and enjoyment of the experience, $r(134)=0.40, p=0.000$.

5. There is a significant positive correlation between easiness of content and readiness to take exams, $r(134)=0.39, p=0.000$.

6. There is a significant negative correlation between communication with professors and levels of stress for D-learners, $r(134)=-0.20, p=0.014$.

\section{Discussion}

The study of D-learning experience in MIU concludes that 14 out of 19 surveyed items have scored satisfactory results (based on index reference) while 5 require redressing by the university and the ministry. The average mean for the 4 rubrics (accessibility, autonomy, retention and psychological impact) has scored 3.35 , which is generally reassuring and subject to positive change post the confinement.

At the level of reaction, the surveyed items may have scored satisfactory levels, yet there is a lot to be done to improve the D-learning experience for students. Because the students did not benefit from any initiative that promotes accessibility to internet and laptop such as Nafida (launched in 2008), they were left to their own financial capacity to provide one. For many years, Nafida provided access to internet and multimedia resources for public schools and subsidised the purchase of laptops and internet connection for students and teachers. This initiative would have made a lot of difference had it been relaunched during the pandemic. The ministry claims that a newly signed agreement with three Moroccan phone and data operators should allow free access to the platforms created by schools and universities, still access to video content (uploaded on YouTube) is restricted and not covered by the pact. 
The missing direct communication with some professors has contributed to magnifying the learning challenges for some students (see Table 6). Accessibility to apparatus and internet does not seem to be sufficient for the learning process to be effective. The D-learning model is a new for many professors and most of the students, so when challenges surface the blame is often put on the process as whole that is, then, seen not effective. Exploiting every communication medium, by both parties, helps to draw a much clearer idea about the ends that should be met. The challenges that go mishandled will eventually lead to losing confidence in the utility of D-learning and even in the students' self-efficacy.

As the study reveals a sense of fear by students, or at least aversion, of prolonging studies remotely, there is a good reason to believe that networking with professors and students would lead to maintaining social ties that alleviate tension. Once online communication with professors and peers is established, approaching learning difficulties would be more positive. The only rubric that did not attain index reference 4, or above, is that of psychological impact. It is perfectly logical to assert that the mounting learning difficulties prevent the enjoyment of Dlearning experience. The widely recognised motivation that accompanies the use of ICT for learning (Ismaili 2020) is spoiled by the challenges that accumulate.

Finally, it is repeatedly reported in the survey that the students' household conditions do not help in the process of D-learning. Although the feedback of the sample population does not elaborate on the nature of nuisance they feel, the study recommends adopting a blended/hybrid scenario that reduces the time of physical interaction at school, yet it maintains a minimum of social ties that are essential for the students' psychological health.

\section{Study Limitations}

Although the study adopts a mixed method approach, the qualitative dimension remains limited. Direct interviews with the students at the time of lockdown when the disturbances (cognitive and emotional) were reaching their topmost could have drawn a much clearer and real-time image about the students' reactions. Despite the fact that the teachers' perspective is not focal in this study, it is of paramount importance for future related studies to investigate this axis in order to connect the dots and devise effective D-learning solutions.

\section{Conclusions}

This study comes to investigate areas of success and failure for the D-learning scenario proposed under the compelling conditions of COVID-19 lockdown. It is a real-time evaluation of a learning strategy that has long been considered complementary and optional for students whose particular professional or personal conditions do not allow attending in-person classes. Probably the lockdown will not last forever, but the D-learning model is being, certainly, reconsidered as a Plan A constituent by many governments and education departments around the 
world that are now compulsorily invited to examine their ICT assets. Although Kirkpatrick (2009) asserts that the four levels of evaluation (reaction, learning, behaviour, results) may not necessarily be conducted consecutively, doing so is primordial to shaping a better understanding of a programme's effectiveness. The success or failure to deliver is conditioned by the abundance of investment in the infrastructure and learning environment. This study has examined interrelated and interdependent variables of the D-learning experience in MIU at the level of reaction and learning and concluded that:

- The MIU students' satisfaction with the D-learning experience is conditioned by their ownership of decent quality gadgets and internet connection. Failure to help underprivileged students in this regard would leave them lagging behind their peers. When technology is available, it contributes to making the best of one's autolearning skills (Voogt and Pelgrum 2005).

- Whenever the university's platform content is easily understood, by means of virtual chatrooms for instance, it is noted that the students' motivation to engage in the D-learning experience jumps higher.

- The student's enjoyment of the D-learning experience relies heavily on the student's feeling of autonomy and ability to solve problems on their own.

- The students can get their confidence back only when they have a good command of the syllabus and are permanently guided. Again, stronger and direct contact with teachers can help in the process.

- The more communication with professors, which is below satisfactory in our case, increases, the lower levels of anxiety and stress can get. Communication at this point is not only a scholarly catalyst but also a psychostimulant agent.

\section{References}

Andresen BB, Van den Brink K, Abbott C (2002) Multimedia in education. Specialised training course. IITE MOSCOW: UNESCO Publications.

Bouziane A (2019) ELT issues in Morocco: a research-based perspective. In MATE ELT Series: Book 4, 137-149. Moroccan Association of Teachers of English (MATE).

Elaasri, R., \& Bouziane, A. (2019). Applying the Quality Matters (QM) ${ }^{\mathrm{TM}}$ Rubric to Analyze the Quality of ENT Platform Courses. European Journal of Open Education and E-Learning Studies, 4(2), 12-22.

Ennda F (2010) Programme GENIE premier bilan de la stratégie 2009-2013 (GENIE program first assessment of the 2009-2013 strategy). Retrieved from: https://www.maghress.com/fr/lesoir/10161. [Accessed 14 February 2021]

Gonzalez T, de la Rubia MA, Hincz KP, Comas-Lopez M, Subirats L, Fort S, et al. (2020) Influence of COVID-19 confinement on students' performance in higher education. PLOS ONE 15(10): e0239490.

Ismaili J (2020) Evaluation of information and communication technology in education programs for middle and high schools: GENIE program as a case study. Education and Information Technologies 25(2): 5067-5086. 
Ismaili J, Ouazzani Ibrahimi E (2017) Mobile learning as alternative to assistive technology devices for special needs students. Education and Information Technologies 22(3): 883-899.

Kirkpatrick D (1996) Great ideas revisited. Training \& Development 50(1): 54-60.

Kirkpatrick DL (2009) Implementing the four levels: a practical guide for effective evaluation of training programs: easyread super large $24 p t$ edition. ReadHowYouWant.Com.

Kirkpatrick DL, Kirkpatrick J (2006) Evaluating training programs: the four levels. Williston: Berrett-Koehler.

MapNews (2021) Distance learning has contributed to improvement of school and teacher image (Minister). Retrieved from: https://www.mapnews.ma/en/actualites/so cial/distance-learning-has-contributed-improvement-school-and-teacher-imageminister. [Accessed 14 February 2021]

Minister of National Education (2021) Morocco reacted 'very early' to COVID-19 pandemic. Retrieved from: https://www.maroc.ma/en/news/morocco-reacted-veryearly-covid-19-pandemic-minister-national-education. [Accessed 12 February 2021]

Moldovan L (2016) Training outcome evaluation model. Procedia Technology 22(Dec): $1184-1190$.

Osman ME (2020) Global impact of COVID-19 on education systems: the emergency remote teaching at Sultan Qaboos University. Journal of Education for Teaching 46(4): 463-471.

Oubibi M, Wei PZ (2017) Chinese and Moroccan higher education MOOCs: rationale, implementation and challenges. The International Journal of E-Learning and Educational Technologies in the Digital Media 3(1): 31-34.

Riyami B, Mansouri K, Poirier F (2016) Towards integrating MOOC in the Moroccan higher educational system: economic pedagogical model based on ICT for on-going education and teacher motivation. In ICERI 2016, 6867-6873. November 2016, Seville, Spain.

Scull J, Phillips M, Sharma U, Garnier K (2020) Innovations in teacher education at the time of COVID-19: an Australian perspective. Journal of Education for Teaching 46(4): 497-506.

Tamkin P, Yarnall J, Kerrin M (2002) Kirkpatrick and beyond: a review of models of training evaluation. Brighton, England: Institute for Employment Studies.

Voogt J, Pelgrum H (2005) ICT and curriculum change. Human Technology: An Interdisciplinary Journal on Humans in ICT Environments 1(2): 157-175.

World Economic Forum (2020) The COVID-19 pandemic has changed education forever. This is how. Retrieved from: https://www.weforum.org/agenda/2020/04/coronaviruseducation-global-covid19-online-digital-learning/. [Accessed 8 May 2020] 
